\title{
The Panopticon reaches within: how digital technology turns us inside out
}

\author{
Ann Light
}

Received: 6 July 2009 / Accepted: 10 June 2010 /Published online: 23 June 2010

(C) The Author(s) 2010. This article is published with open access at Springerlink.com

\begin{abstract}
The convergence of biomedical and information technology holds the potential to alter the discourses of identity, or as is argued here, to turn us inside out. The advent of digital networks makes it possible to 'see inside' people in ways not anticipated and thus create new performance arenas for the expression of identity. Drawing on the ideas of Butler and Foucault and theories of performativity, this paper examines a new context for human-computer interaction and articulates potentially disturbing issues with monitoring health rather than wellbeing. It argues that by adopting explicitly social framings we can see beyond the idea of medical interventions for health to recognize the political implications of the new categorizations and their implementation in code. In the process, it critiques traditional ways of understanding machine-body relations within the field of technology design.
\end{abstract}

Keywords Performativity $\cdot$ Bodies $\cdot$ Biomedical $\cdot$ Cyborg $\cdot$ Health $\cdot$ Wellbeing

\section{Introduction}

Research is being conducted on wellbeing and healthcare to provide new interfaces with the body (eg Leonhardt 2006). This very embodied technology manifests as sensors, monitors and control dashboards with technical feedback loops that allow the person and/or their medical care team to review new types of data in new ways and then adjust lifestyle or treatment regimes accordingly. Increasingly, small monitors can be placed inside rather than upon a person to investigate a condition. These new developments have the potential to make access to information that was formerly only occasionally available into part of the routine of our everyday lives. Although considerable work has been focused on both the ethics and the

\footnotetext{
A. Light $(\bowtie)$

Sheffield Hallam University, Sheffield, England, UK

e-mail: a.light@shu.ac.uk
} 
practicalities of privacy in medical contexts, such as data protection for patient records (Brown and Adams 2007), there is less thought to how we anticipate other socio-political issues, such as the effects of living wired up to the local medical centre. Rodden notably quipped during a keynote vision of the future (2006) that he didn't want a fridge conspiring with his children to stop him having another beer because his blood sugar was getting high. Awareness of health, with the attendant expectation that one will look after it, might seem an incontrovertible good, but carries with it the seeds of new normative behaviours with socio-political potentials.

The complex relation between the human body (particularly its internal function) and possible new social behaviours is difficult to articulate within traditional design conceptions of humans as technology users. The notion of 'user' directs our thinking about impact into a simple machine-person dynamic that is divorced from broader societal matters, presenting technology apolitically and suggesting that people are passive in their engagement with it.

In contrast, in this paper, I propose a way of articulating these social elements, drawing on theories of performativity (Butler 1990) both as a means of showing impact on the experience and the discourses of identity, and as a means of keeping people's agency in the discussion. Additionally, I suggest that we can explore technology's engagement with bodily practices fruitfully by seeing them as a performance for self and others. I do this in full awareness that human beings have considerably less control over ways of being and doing inside the body than over external manifestations. However, both concepts present people dynamically, being changed and changing others as a matter of course. The notion of performativity is used here to understand the doing of identity. The notion of performance is presented as a way to understand the interactions possible in specific contexts. Looking this way, the constraints and the opportunities that exist despite these constraints can be brought into relief.

To set the scene for this argument, I identify a set of technological convergences making internal physical states available for interpretation:

- Networked/ubiquitous computing: the means of joining together information from different sources, transmitting it and using it differentially.

- Processing power to do data mining: extracting specified information (such as heart rate, brain waves and gastric processing) from vast reserves.

- Advances in Genetic Science including the human genome project: giving rise to new correlations (like disease and genetic coding) and genetic difference across social categories (such as race and sex/gender).

- Nanotechnology: intervention on a scale that allows new sites of monitoring, particularly of the internal human state by implantation.

Using this backdrop, I will discuss the marriage of actuarial insights in real time as a new bio-political arena of identity and for performance; inside the skin.

This paper hopes to tease out a new way of viewing our mediations in the area of technology for personal monitoring. To do so, I intend to first address the tools I am using, which in this case are theoretical approaches to understanding identity; then look at how people interact with technologies to constrain or extend themselves, before examining how close these approaches come to the methods used in design practice. I then turn to the central discussion: of health and technology, considering 
perspectives, practices and probes and asking a series of questions that emanate from taking the theoretical approaches described, before concluding with an exploration of what possible impact machines might have on how we understand ourselves and what power we have to resist this.

\section{Identity, agency and technology—some definitions}

Before launching into a full discussion of the issues raised by new technologies for health, I here lay out my use of terms such as identity, agency and so on, a task complicated by my desire to use post-structural theory instrumentally to challenge design practices and outcomes.

This paper is concerned with a distinction between what can be seen of the body at present: ie, what can be viewed on the skin, extracted to be examined (as happens in biopsies) or opened to view by cutting, and what can be investigated internally and assessed continuously in real time by the new interventions becoming possible. I have called this 'turning identity inside out' though of course this is an exaggeration. But the distinction, I will argue, has significance for how digital technologies might contribute to a change in our understanding of who we are. Further, it has design implications - ones that reach beyond the machinery of the new tools to how they are coded and embedded in society. But, of course, this tale of inside and outside neither claims to be the whole story of human identity, nor to address the boundaries of the person or self. What I would claim is that, even with a philosophical framing that emphasizes how discourses create experience, there is still the matter of bodies and our relationship with our own and others. And that, when we use certain tools to extend our reach, there become two layers of interpretation to deal with: that of perceiving and that of the machinery we use to 'see inside'. The latter is political, not least because of its relationship with the former. I will return to this theme later; here it is enough to identify skin as a kind of boundary, but not the only one.

My next key concept is performativity, closely tied up with identity. In discussing the creation of identity, Butler reflects on performativity, not in its incarnation as speech acts (Austin 1962) impacting on the world, but as inscription on the body through repeated enactment.

One is not simply a body, but, in some very key sense, one does one's body and, indeed, one does one's body differently from one's contemporaries and from one's embodied predecessors and successors as well. (Butler 1990:272).

But this is not to choose one's identity. Butler sees this as subject to the norms of society and thus a rehearsal of particular discourses in flesh. Discussing de Beauvoir, Butler explores the body as situation, as both "a locus of cultural interpretations" and the "situation of having to take up and interpret that set of received interpretations" (1985). In this way, she suggests the control, and lack of control, people have to perform their bodies. Butler can be read as profoundly concerned with embodiment or criticized for removing the significance of materiality from a discussion of identity. I choose a reading here that stresses the former and use her insights to discuss the way that identity is written upon 
individuals' bodies and identities in particular confluences by the practices of self and others and it is this set of interactions that inscribes, prescribes and proscribes who we can become. ${ }^{1}$

In talking about performativity, we are talking about something quite distinct from performance, however in this paper I make reference to both concepts. The former is useful here as a way of understanding the relations between society and identity, of how practices constitute us. Whereas, by contrast, the notion of performance has no 'becoming' associated with it. It is the act of doing and useful here because I do not wish to talk only about long term processes, but to dissect the doings of the body. To do this, I need a vocabulary in which to express our expressions and performance offers a suitably rich language about interaction.

The term 'identity' in the discourses of the technical realm can be understood in multiple ways and a common reading is as identifier of a unique component in the system rather than as a socially created diverse personal phenomenon. If I talk about identity management in this paper, I do so in the broadest sense and although my context is the advent of the internet of things and I am addressing some of the same digital developments that have brought this other use of identity into play, I will not be regarding it solely as a way of sorting metadata about objects or people in the system.

It is also worth saying a word about agency. This issue of agency — or our power to do-is core to identity: how far (we believe) we choose our means of presentation and how this relates to who we think we are. Butler's later work articulates this relationship most simply:

not only does one need the social world to be a certain way in order to lay claim to what is one's own, but it turns out that what is one's own is always from the start dependent upon what is not one's own, the social conditions by which autonomy is, strangely, dispossessed and undone. (2004:100)

The relationship of agency, technology and identity will come up repeatedly here. For the purposes of this paper, I am following Johnson (2006):

Computer systems are components in human moral action. When humans act with artifacts, their actions are constituted by the intentionality and efficacy of the artifact which, in turn, has been constituted by the intentionality and efficacy of the artifact designer. All three components-artifact designer, artifact, and artifact user - are at work when there is an action and all three should be the focus of moral evaluation. (Johnson 2006: 195)

\footnotetext{
${ }^{1}$ This non-essentialist view of identity is important here for if we see identity as something intrinsic and fixed, patterns of societal behaviour have no influence and there can be no impact from radical changes in them. Clearly this is not the case - a quick consideration of the appearance of 'psychology' as a discipline and with it a progressive redefinition of mental states and processes will show the important relationship between how we label ourselves, how we understand ourselves and how we behave. Though this is not to claim that the arrival of the new discipline in the late $1800 \mathrm{~s}$ effected the change... it represented a novel interpretation of human life that gradually allowed and fed a different way of thinking about behaviour and, with it, different behaviours.
} 
while acknowledging the work in this area by Barad (2007) and Latour. Indeed, we might see this position as my 'practical metaphysics' (Latour 2005). ${ }^{2}$

\section{Technologies of identity}

So, do the technologies we construct as civilizations have any bearing on who we become as individuals? There is a body of literature that suggests technology offers the means both to conscribe and extend the enactment of identity. If we look at Stiegler's (1998) development of Heidegger's phenomenology, we find a claim that technics ('the organisation of inorganic matter') is primordial to human experience in the same way as temporality or spatiality. He argues that the evolutionary development of the human being, was/is a process of externalisation —or the 'pursuit of life by means other than life' (1998) made possible through language, technique, and culture - that allows us to capture and share our existence. Organization is a key aspect here. Through the act of organizing, we are able to constitute the world, but these organizations fasten interpretations upon matter and thought. In so doing, we deprioritize or exclude other interpretations - a fundamental of categorization. As Bowker and Star (1999) poignantly describe, categorization systems have formed identities for people through increasing bureaucratization and political definitions like apartheid. Although these identities may then exist as identifiers, the social processes from which they emerge and which they then reinforce, are part of the inscription process described above and so have bearing on what we do as well as how we are known.

Making categories is technical, yet the act does not require particular technological implementations to be divisive. When we talk about implementation in digital technology, we are considering a new dimension because of the digitization of the systems we are discussing. At its simplest, this is the way that these systems are supported by (and made inflexible through) software implementation. At a fundamental level, computation does not tolerate ambiguity or negotiation in interpretation. Computer systems have to be designed to accept humans' 'fuzzy logic' and, by and large, ordering is seen as one of their virtues. So, in putting social systems into code, categories become less open, with attendant loss of space for deviation (see Light 2007). When information technologies, in their rigid underlying hierarchies and formal definitions, meet binary coding and hard-wiring, this alters the balance of control in interpreting and inventing oneself afresh. It is also worth noting that social and financial investment in computerware is often such that it brings with it a reluctance to consider change. So the impact of the technology is twofold. First, there is the disambiguation of the digital form; second, there is the commitment to particular, not necessarily optimized, versions of it. The lock-in of

\footnotetext{
'Barad's 'agential realism' (2007) addresses agency and materiality by showing that how we apportion agency is both political and an intra-active effect of what we are doing and the tools we are using to do it in the particular context of action. The 'cut' we make in the fabric of the world has material consequences for how we understand the relationship between tool and outcome. Latour (2005) looks upon individuals' attributions of agency as 'real', given that these represent their understanding of the structure of the world and for Latour there is no single consistent version of reality. We might see my reasoning here as an example of a deliberate cut to support a particular argument and view it, with Latour, as 'real' for our purposes.
} 
starting a formal system in one way is profound and can be seen in how the prospect of swapping operating system inhibits the growth of alternatives. Once the interpretation is made, the time and money invested in it become a particular way of seeing and the overheads of reconsidering the underlying structure become a force for inertia - both in the narrow technical system and potentially also then within the wider socio-technical one that it feeds into. And with the investment in a particular system come new gatekeepers for us to convince that change is needed and new procedures to follow to initiate change. In this way, technical choices give birth to new social organizations to police them.

So these categorization systems organize our world, allowing for certain kinds of creativity while limiting our flexibility in other ways, but the phenomenologist literature also gives accounts of how tools extend bodily function and boundaries and thus impact on identity: notably demonstrated by Merleau Ponty's example of a blind man whose cane extends the scope and radius of touch (1962). Knowledge about the cane is mediated by its primary value to ascertain the positions of objects being touched; it is known by what it conveys, its process of extension disappears and its particular focus and functions become written out of our thoughts. This is interesting for the invisibility (and thus de-politicization in use) it implies of the functioning tool. It is only the breakdown of the tool that causes us to notice its nature again (Heidegger 1962).

It is also interesting to consider how these 'extensions' may be playfully expressive. In Haraway's cyborg (1991), the technologically enhanced individual, and in Plant's posthuman condition, where body and technology meet (1997), we have further theorizations of technology and embodiment that give a positive though not uncritical response to the question of how organic and inorganic systems mix. And contemporary art plays with these boundaries. For instance, Gonsalves' Chameleon project (2009) uses 'mind reading technology' to assess, provoke and respond to emotional states in the audience. 'When participating in "Chameleon", individuals become intimately connected and implicated into varying emotionally provocative and reflexive social interactions'. Experience of Chameleon's eight prototypes, produced internationally with a range of collaborating scientists and technologists, is intended to leave the participants with a further understanding of how their own non-verbal communications have an impact upon social groups, and guide the formation of empathy. Yet it is not a prescriptive form of intervention demanding that people contribute in a specific way. It is an art project, with the desire to captivate, amuse and trouble as well as inform. In this way it can be seen to differ from forms like the clinical trial or a user test: it is positioned as a means of stirring up responses to an intriguing phenomenon. Art projects of this kind demonstrate a form of serious play with the potential of the body in their experimentations. I will return to this theme.

\section{Performance and designing technology}

The concept of performativity has not affected the design of technologies in the same way that it has impacted on sociological analysis of relations with technology (eg Law and Singleton 2000). By contrast, the idea of performance has been used in understanding specific interactions with technology as a prelude to designing. There 
is the use of actual performances or methods drawn from drama, theatre and performance art (eg Light et al. 2008, Newell et al. 2006), and the extensive use of scenarios and personas, but this does not concern us here. Another strand has used performance as a metaphor for people's engagement with technology (Healey and Light 2007, Dalsgaard and Hansen 2008). The work of Goffman (1959) has been extensively adopted by researchers into human-computer interaction as a way of understanding how people construct their relations with others and more specifically how they present themselves. For instance, the idea of being back- or front-stage in performance terms while in company has been taken on (eg Hulme and Truch 2005), particularly in exploring the use of mobile phones. People seek to choose the level of informality and intimacy they show in the presence of different parties. (And we can observe that most people feel their insides should be backstage, ie a topic only for those they know and trust.)

Healey and Light (2007) make a crucial distinction between 'performing' as the designer of an artifact intended and the potential appropriation of the artifact for performing as social display. Both they and (Dalsgaard and Hansen 2008) give the example of Dance Dance Revolution (DDR), an arcade game with a platform where two dancers compete with each other in front of a scoreboard that also dictates their next move. DDR is not used as conceived because the shared aesthetics of dancing in public was overlooked in the design. Consequently, features are used in unanticipated ways for acquiring social standing, such as encouraging an audience, dancing facing the audience not the screen, and dancing in sequential competition, rather than with a direct competitor in parallel (Healey and Light 2007). In reflecting upon the social engagement around the tool, Healey and Light look beyond a common use of performance for exploring human-machine relations and implicitly touch on the nature of performativity. Here I go further, beyond the traditional arenas for 'doing', to consider what happens when monitors and sensors bring machines into the body and into the assessment of the resulting data, so that new contexts of 'doing' are exposed to gaze and, with it, value judgments.

\section{Performing as a healthy being}

As noted, one feature of Butler's analysis of how identity (for her, specifically gender) becomes created is the way that it is reinforced by our engagement with and (re)production of social norms. Leaving aside a discussion of what constitutes health as such, we now consider how social norms might function in the realm of heath and wellbeing.

In treating conditions such as diabetes ${ }^{3}$, the uses of automatic devices which monitor and inject insulin unquestionably provide support and safety, and may save lives. At present, most people see static glimpses of their glucose levels rather than a flow of data. But there are very different interfaces possible, such as chips that report continuously and toilets that automatically measure users' urine. (Which begs the question of what happens when someone innocently uses that device for its primary

\footnotetext{
${ }^{3}$ See Armstrong (1991) for a discussion of social factors associated specifically with diabetes care. We are taking it here as an example of an area in which monitoring is already heavily embedded.
} 
purpose and incidentally finds out about levels in their body...) All these systems presuppose making data on the body's condition available. It would be possible to design a system of intervention in which the user never needs to consider the data. An embedded chip that controls a reservoir of insulin (or some catalyst of the future) would operate as 'black-box' technology which has no educational function and gives no representation of what it is doing. This opacity could possibly prove dangerous for the user, especially in the case of a malfunction (though perhaps no more so than taking medication unquestioningly at a doctor's say-so). So, we may suppose that good design involves a trade-off between the visibility of function and data and the ease of use. The case of particular interest here is when there is feedback about the body's behaviour, before and after interventions, to those with a duty of care for it. Our questions in the context of discussing impact on social norms include: What happens in the feedback cycle when such devices monitor continuously and report routinely on the body's condition, either to the person or to professionals? For instance, whose knowledge is it that a run of fish and chips has affected insulin levels? And whose authority prevails if anything should be done differently as a consequence of making this data available?

Let us take a more ambivalent example: what happens when the heart is routinely reporting on its condition as part of a preventative package where no particular medical condition has been established? Armstrong (1995) talks of the shift from distinct categories of healthy and ill to a "realization of a new public health dream of surveillance in which everyone is brought into the vision of the benevolent eye of medicine through the medicalisation of every life" (1995:399). His "surveillance medicine" (1995) looks for recursive "risk factors", as one condition is indicative of risk of another and we all live in a pre-illness at-risk state. And Dumit (2010) considers the tyranny of pharmaceutical clinical trials over understandings of health. Findings from trials are regularly used to redraw the bar at which the populace is seen as needing treatment for likelihood of conditions: actuarial risk reified into symptoms. Meanwhile, his analysis of the flawed basis of using these trials to decide healthcare and the way that findings suit the pharmaceutical companies' commercial interests starkly reveals the political and economic nature of the metrics that come to be employed to determine what 'healthy' is.

Particularly with this shift from the absence of overt illness towards health as a series of risk factors, we must ask if the monitored person has the 'right' to live badly in the eyes of the medical profession and the wider populace and whether 'bad' behavior should affect access to treatment or the cost of life insurance. We could argue that, designed in or not, health gadgets have a role to persuade (take your tablets; eat less fat). The Wattson (-nd), an energy meter that shows a household's consumption at any given moment in a single prominent reading, was designed for behaviour change. By a similar means, body monitoring can lead to societal pressures akin to those toward green living, by accident or by design as part of the fulfillment of a public health dream.

Foucault (1975), in his analysis of power relations, traces the historical journey of punishment away from the visceral subjugation of the body to remote but pervasive monitoring and the internalized fear of punishment that one found in Victorian prisons. He identifies a shift in the nature of institutions including both prisons and hospitals towards using an "inspecting gaze, a gaze which each individual under its 
weight will end by interiorising to the point that he is his own overseer, each individual thus exercising this surveillance over, and against, himself' (1980). This idea has been taken up in the sociology of health (for instance, Armstrong 1983), while Bauer and Olsen offer a post-panoptic discussion of medical surveillance (2009) and Rich and Miah (2009) discuss the formation of the medical gaze in cyberspace. Foucault (1975) suggests that mere awareness that a controlling agent might be monitoring everyone at all times promotes individuals' compliance with the rules of the system. If we adopt this central idea of internalizing the censorship of behavior, we can see that by putting human-technology interfaces into the body, we are led back to the physical contact that we see in subjugation, but, at the same time, we are obliged to consider a panopticon-style condition of potential all-round remote supervision. By likening the intrusion of observation technologies to this panopticon, we highlight both the new arena for inspection that these tools introduce and the performative attributes of internal readings, thereby raising the issue of conformity for those monitored and how it is arrived at.

The panopticon is not the only metaphor used to explore the effect of the digital society on individuals' feelings and sense of self-determination. Solove (2004) juxtaposes Nineteen Eighty-Four's Big Brother (ie. Orwell's panopticon vison of the future 1949) with Kafka's faceless, bureaucratic and bewildering processes in The Trial (1925) as a way of discussing the potential social pressures introduced by database mining. He argues that a shortcoming with the Big Brother metaphor is that it focuses upon surveillance and much use of database material is other than that.

The goal of much data collection by marketers aims not at suppressing individuality but at studying and exploiting it. The most insidious aspect of the surveillance of Big Brother is missing in the context of databases: human judgment about the activities being observed (or the fear of that judgment). Surveillance leads to conformity, inhibition and self censorship in situations where it is likely to involve human judgment. (Solove 2004: 34).

He offers instead a vision where people have lost control over the use of their information, where decisions are made without their knowledge and everyone is at the mercy of indifferent bureaucratic processes. Clearly, both metaphors have something to offer the discussion here. What is of interest is the internalization of societal judgments and the anticipatory process of normalization of our internal behaviours to fit the normative ideals of our institutions, such as clinics and health insurance companies.

Questions arise in taking this perspective which reach beyond intervention, safety and privacy to wider social understandings of observation and agency, such as:

- Who is the audience for an internal view of what my body does?

- How do I want to portray myself and what scope exists to choose a portrayal?

- Am I empowered to resist others' readings of my condition?

- Can I deceive my audience? Can I deceive myself in this inside-out world?

- Can I manipulate myself or the audience to make them empathize, to want to help or to praise or to critique?

- What is the impact of my new visibility upon my sense of self and wellbeing? 
As Mireille Hildebrandt points out, the resistance alluded to in some of these questions calls to mind Mead's work on the difference between 'play' and 'the game' as they contribute to the development of the individual (Mead 1934). We have already made reference to the artist's role to play seriously with the potential of technology. This is not to succumb to any conforming or normalizing tendencies, but rather to enjoy the range of roles it is possible to experiment with and perform asin Mead's view, the playful behaviour of a child learning about the experience of the other. Here, though, we have to see the performance as that of a role in a prescribed system and any attempt to resist, sabotage or do mischief to the dominant order as part of trying to change the rules of a game, rather than as free-form play. Mead draws attention to the game's role in finding a perspective on oneself as seen by others and adapting to the social organization in which we are maturing. It is this relationship with others' attitudes that makes his analysis of games so relevant here. And we can see that it takes a strong insight into the nature of the game to be able to propose alternative rules and perform a role even partially of one's choice. We might suppose that, with its combination of sophisticated technology and biomedical personal data, this will be a difficult game for people to understand sufficiently well to impose much mischief upon.

Performing in networks where machines watch over us

So we can describe the penetration by medical monitoring equipment as having performative elements: 'doing' one's body among the omniscient audiences of ubiquitous and nano- technologies that would inscribe new discourse patterns upon us. And we can see the performances of resistance we strive to give in answer as part of a challenging game. But who is the audience? Who is looking into our bodies? In Hildebrandt's words: who is profiling who? (2009). In the networked world, the performance of health may be interpreted by society, but its first 'audience' is a machine with the capacity to make connections between streams of data, flash up key intersections and store patterns. In other words, the new audience-a digital networkis forming remote judgments about the nature of the individual. We can argue about the language here; for the language suggests agency on the part of computers. But data mining for patterns and then acting upon them is a form of interpretation and judgment making, even if it is one based on programming and not one that happens in real time: if not agents, they are what Johnson (2006) calls 'moral entities'.

We can frame a further set of questions in contemplating this prospect: What kind of audience are the computers designed to be? Intelligent? Sympathetic? Empathetic? And, remembering that there are rules to this game, how do we as performers to this audience know what cues they will respond to or how they will interpret our signals in order to make judgments on the quality and acceptability of our performance? Can we control these cues? Do we have the skills and knowledge to perfect the performance we would want to give? Are there critics in the wings who stand in judgment of both audience and performers? ${ }^{4}$

\footnotetext{
${ }^{4}$ A further set of questions that we might want to ask includes: When might we appeal that we would be better served by human evaluation? Indeed, which contexts are best left to human perception and appreciation?
} 
Whereas when I use Dance Dance Revolution, whether I dance, how I dance and what I wear are all familiar choices that I make in deciding to step onto the machine, I have less awareness of options and less creativity in how I 'do' my internal body. I am largely stuck with my inheritance, certainly over the short term. Does this matter? After all, we can reflect that, as an audience, a machine is impersonal and apparently even apolitical in the face of the limits of my bodily performance. A machine does not process identity based on appearance and those qualitative aspects that humans use to form judgments, but instead finds its rationale in processing metrics and so is easily argued to be fairer in its dealings with diverse populations. However, inevitably these ostensibly neutral quantitative approaches operate with embedded political readings of information and how it should be manipulated. For instance, statistical genetic information will be more interesting to a machine than what lies on the skin or, indeed, our skin colour. But the use of statistical genetic data relating to race will, in itself, be politically charged, as would any embedded interpretative formulae used in an analytic system. Hildebrandt (2009) talks of "invisible visibility" to describe the state where data on health-risks, earning capacity and other personalized profiles create the possibility for sophisticated social sorting, requiring concern for illegitimate discrimination. I have already referred to some of the vested interests and the economic motivations in presenting health information in certain ways. The very decision to make things readable by machines is also political, regardless of the idealism of their creators or whether the people purchasing them believe that the latest in healthcare methods on the market must be the best for patients as well as demonstrating the world-leading stature of their facilities. Yet Virilio's military-scientific vision (1996) holds up these intrusions into the body, or his "transplant revolution", as endo-colonization: the occupation by a state of its own people, a condition that necessarily starts with the subjugation of the body.

What kind of body does a person want to 'do' in this context? It is not easy to predict, even if a warning about sickle cell anaemia would be useful...but asking brings us closer to an answer.

\section{If robots rule the world}

I have been presenting a developing trend in technological mediation and a way of framing it so that the implications can be seen in social terms. Much ethical discussion of how technology mediates in health contexts concerns privacy. This paper is about something else, both more subtle and longer-term in its impact. Just as DDR was not conceived to be about performing socially, neither are the tools here and yet we can see they offer this opportunity. However, whereas the dancers using DDR can choose a public image to 'do' even if they cannot choose their spectators, the panopticon is imposed from outside into a space where genetics and phenotype are not to be easily tampered with and thus we have even less recourse to (re) inventing ourselves. Our biological entities may be the subject of different philosophical and scientific interpretations but the organs and genetic formations on which these interpretations are based have consistent physical manifestation and their performance changes only slowly in response to changes in lifestyle and within 
certain parameters. Butler argues that our performance of identity is arrived at through different confluences of social inscription, rather than unconstrained choice. I argue here that monitoring of health constrains our choices of presentation further and should be developed with this thought in mind. It is not an argument against providing this kind of support to either groups defined as ill or those considered to benefit from preventive and early warning help (which includes the rest of us). It is an argument about how it is designed and how far identity issues are considered along with the more usual areas of privacy, usability and acceptability.

We might reflect that there is a distinction between wellbeing tools and (public) health tools. In designing techno-medical interventions, is our highest purpose to support individual wellbeing? (Arguably, it may be to keep the cost of the welfare system down and release funds for other uses in the community. To sell more drugs (Dumit 2010). Or, as Virilio (1996) argues, it might be another form of militarism.) We can note how much is spent on cigarettes and alcohol by some households, and that addiction alone is inadequate to explain this in the face of all the health information suggesting that both drugs cause disease and can kill. Clearly, there are sites of resistance to health information where short-term pleasure and other factors predominate. It is not my place to argue about these lifestyle choices or discuss the implications these practices have for child-rearing, etc., but to recognize that persuasion needs fertile ground and that conditions for conditioning do not affect all people in the same way. But I am also making the point that people's greatest good may not be served by the pressure to conform in yet another arena: anxiety about obesity may not be the best cure.

Returning to the greater theme of how aspects of identity might be fundamentally redefined by the interactions that surround a new wave of technology, we can trace an increasing bureaucratization and situate the development of computer systems that process people as health feedback systems as part of this tendency (see, for instance, Bauman (1991) on modernity as well as Bowker and Star 1999). Passports and social security numbers situate people, as do the surveillance systems that manifest in CCTV and mobile phone data. These tools can be used to track people's behaviour at different levels of granularity. But monitoring the body for health is qualitatively different from situating it because of the element of internal scrutiny. It accentuates the difference between performance on the one hand, which is merely an expression in a particular moment or at a particular place, and performativity as construed here, which concerns the mark we leave and are left with as an accumulation of interactions over time.

Using the notion of performativity is at once a way of stressing concern with the involuntariness of much of what happens inside us and a means of considering it that offers some hope of resistance. This argument seems at first inconsistent but it hinges on the idea that anything which is understood to be active is also ultimately dynamic, and that anything which can be altered by greater powers can also be more subtly shifted by an awareness of those powers at work and a mindfulness to their effects. It is to contemplate the way we speak about something as having an impact, in terms of our expectations but also in terms of how society orientates to it and thus what frames our longer term engagements. It is to explore the agency of the discourses that form us as part of exploring our performance of our bodily matter. 
We cannot control insulin levels in a way comparable to adjusting our gait or our location. Yes, there is a causal relation to eating, but not an intentional effect. This means a boundary has been crossed. We do a kind of performance with our bodies, but we do so without much of the control that is normally associated with human performance. Our options to affect our 'biological' behaviour are limited in the short-term. We can choose to breathe more slowly and manage our heart rate. We rub our temples and improve the blood flow to the brain. We do not affect our endocrinal system similarly. It requires chemical intervention that might be the impact of years of yoga training, or might be from food or medicine. Without claiming that the internal body is natural, to be apprehended without interpretation or immune to cultural trends, we are in a different landscape here. What is inside us cannot be manipulated as easily as what manifests from it: we cannot make our hair follicles sprout in the same way that we can affect a style, a colour or a cut of hair.

Yet plenty of patent medicine exists to help us overcome this limitation because the appearance of our hair is deemed significant. In other words, pressure exists to manipulate ourselves where it counts and what is shifting is the line between what counts, ie is discernible as part of who we present as, and what does not. So it is likely that we will begin to change our behaviour with our bodies to meet a new set of agendas. At present, plastic surgery is largely an external phenomenon. Dosing on medicine to keep incipient conditions at bay and minimize predispositions is gaining in popularity, but, wholesale, is still largely a US American phenomenon where preventative medicine is both driven by and can be costed into the insurance model of health. Will this change when we are routinely scrutinized in another arena? The performance of our insides suggests interventions of a kind that many of us currently see as macabre: lifestyle drugs, surgery, genetic modification. Rewriting ourselves driven by new norms and expectations is possible.

Resisting the pressure to improve the health lottery we inherit from our forebears, there will no doubt be people who do not want to know or adjust their internal status, either through the indifference to health, mentioned above, or through some squeamishness about the politics or processes involved. There will be the regimes that cannot afford it, where most of the population is still fighting malaria while the local middle classes start to buy into healthcare models of the affluent and trendy. There may be nations that look at the huge costs to care in other directions and choose a different way (after all, a focus on genetic analysis and machine surveillance would inevitably leave other aspects out, just as Western medicine practices are already charged with ignoring the holism of other systems).

However, the arguments above make clear why performativity is relevant in this discussion. We can predict the paradigm of care shifting and with it the expectations for identity and the way that we do our bodies. This prediction may turn out to be completely misplaced, but in making it, we can recognize the relationship between the potential of technologies, the malleability of the human (self) image and the way that identity is not so much chosen as inscribed by social practices at large in a complex of tensions that these new developments would be adding to. 


\section{A penetrating view}

I mention images of the self and it is with viewing and imagining that this piece ends. The argument in this paper has focused on the idea of audience and being viewed by new means. What was impossible to view in real time and continuously (as we might gaze upon external manifestations of identity) is becoming continuously viewable by a kind of mediated gaze. This shift could be said to continue in a sequence that Ihde (1991) traces through Foucault's work on The Order of Things (1966, quoted in Ihde 1991) and discusses:

By terming the invention of biology as a shift to the "invisible", there is a shift to what had been either not attended to or attended to in a simple, manifest way. Biology does not shift to the invisible, but to a different kind of visibility which Foucault terms quasi-visibility, the internal and the microstructured. But this domain is precisely what the technology-instrumentation-of science made available to the nineteenth century as never before. The new seeing is by means of instrumentation, a not inconsequential phenomenon! It was stimulated in part by the invention of staining techniques, which made visible what was previously invisible even under the microscope. (Ihde 1991:42)

Here we are reminded that it is not new to see through tools to 'understand' ourselves and our world. Ihde's book suggests that the development of science has a much closer relationship with the development of technology than the discourses of science acknowledge. What do our latest technologies afford us? We no longer have to make do with glimpses into our internal condition-not the slices on the microscope or the pinpricked blood in the glucose test. We are reminded again of Foucault's inspecting medical gaze (1980), at once depersonalizing and intrusive, which the medical profession brought into play in replacing nurture by the priests.

Bauer and Olsen talk of the "digitized and transparent individual patient body" (2009, emphasis added) as one pole in the context of this medical gaze. We must look closely at this transparency, for it is important to understand that there never was and never can be any real transparency. Even leaving aside the epistemological impossibility of a transparent state, we must consider the notion of an all-knowing gaze, with Foucault, as part of the station granted historically to the medics rather than as a fact of medical knowledge.

Instead, I am going to bring into service the metaphor of translucency and exploit its quality of partial revelation as a form of "quasi-visibility" (Foucault in Ihde 1991). Our opaque skin is becoming translucent, highlighting some internal readings of ourselves, hinting at and obscuring others. We see through the skin darkly, our view interpreted by machines that we cannot know experientially as we do the bestowing of our own gaze and which most of us do not understand for the political entities that they are, because, in using them, their work becomes invisible to us. What was inside is becoming part of what is held up to public scrutiny and judgment, but not in a way that we are used to seeing and being seen. We might argue that translucency is the worst of all worlds: encouraging interpretation, seemingly knowable and yet obscure. It is not, as presented here, a way of speaking about the inevitable ambiguity of identity; it is, at worst, the clumsy rendering of society's most reductive understandings of personhood, dressed in the language of 
transparency. It is this new discourse that will also be written onto our bodies ... discourse about genetic code and computer code which speaks with the authority of scientific certainty in the face of ostensibly more subjective encounters with subjectivity. This discourse implies that we now know more than we ever did about what a person is, and thus squeezes out the play in the system. If the new person is a 'genetic' person, we have to ask what identity performance is possible. Are we just externally determined metadata in the context of a genetic test and what follows from it? Other, more flexible, interpretations may not only look less authoritative, they may lose footing as machine data floods both personal logs and professional establishments at the expense of different readings of wellbeing and the time to process them. This, then, is the dystopian view.

But let us go back once more to Butler, to follow her in making a means for change amongst the norms bearing down:

to intervene in the name of transformation means precisely to disrupt what has become settled knowledge and knowable reality and to use ...one's unreality to make an otherwise impossible or illegible claim (Butler 2004: 27).

If we choose the active metaphor of 'doing' our bodies (with all that acknowledges about being done to) and adopt a view of agency pragmatically to give us the best 'reality' in which to play out our existence, we resist the illusion of transparency and we can make ourselves a little space in which to experiment and even change the rules of the game. We can offer up alternative and subversive games, as we might come to view Gonsalves' mind reading art. We can read the way we handle our internal matter as a performance. We can select our stories of dystopia for their potential to motivate us. I would like to advocate that understanding of performativity here.

So, this paper uses the device of exploring medical technologies through performativity to encourage new discussions about design and new discourses around identity, presentation and control. Such measures will be critical if we are not thoughtlessly to embed new orthodoxies of behaviour in the code of our creations. I offer this analysis as providing an opportunity to reflect on tools - and connections between them - that allow people to perform themselves inside and out and take the interventionist view that if such designs are to be forthcoming, we should balance function and openness so that people can use what limited scope exists to handle their identity with discretion, decorum and control.

Acknowledgements The author thanks Peter Wright, Jeff Bardzell and Simeon Yates for their comments; and the participants at the second IDIS workshop, especially Mireille Hildebrandt, whom she was fortunate to have as her discussant.

Open Access This article is distributed under the terms of the Creative Commons Attribution Noncommercial License which permits any noncommercial use, distribution, and reproduction in any medium, provided the original author(s) and source are credited.

\section{References}

Armstrong D. Political Anatomy of the Body. Cambridge: Cambridge University Press; 1983.

Armstrong D. The social context of technology in diabetes care: 'compliance' and 'control'. In: Bradley C, Home PD, Christie MJ, editors. The technology of diabetes care. Reading: Harwood; 1991. 
Armstrong D. The rise of surveillance medicine. Sociol Health Illn. 1995;17(3):393-404.

Austin JL. How to do things with words. Oxford: Clarendon; 1962.

Barad K. Meeting the universe halfway: quantum physics and the entanglement of matter and meaning. Duke University Press; 2007.

Bauer S, Olsén JE. Observing the others, watching over oneself: themes of medical surveillance in society. Surveillance \& Society. 2009;6(2):116-27.

Bauman Z. Modernity and the Holocaust. Polity; 1991.

Bowker GC, Star SL. Sorting things out: classification and its consequences. Cambridge: MIT; 1999.

Brown I, Adams AA. The ethical challenges of ubiquitous healthcare. Int Review of Information Ethics. 2007;8:53-60.

Butler J. Variations on sex and gender: Beauvoir, Wittig, and Foucault. PRAXIS International; 1985. Issue 4, p. 505-516.

Butler J. Performative acts and gender constitution: an essay in phenomenology and feminist theory. In: Case S, editor. Performing feminisms: feminist critical theory and theatre. Baltimore: Johns Hopkins UP; 1990.

Butler J. Undoing gender. Routledge; 2004.

Dalsgaard P, Hansen LK. Performing perception-staging aesthetics of interaction. ToCHI, 15; 2008.

Dumit J. Prescription maximization and the accumulation of surplus health in the pharmaceutical industry: the_Biomarx_experiment. In: Rajan KS, editor. Lively capital. Duke University Press; 2010.

Foucault M. Discipline and punish: the birth of the prison. New York: Random House; 1975.

Foucault M. "The eye of power." Power/knowledge: selected interviews and other writings 1972-1977. transl. Gordon C et. al. New York: Pantheon; 1980, p. 146-165.

Goffman E. The presentation of self in everyday life. Penguin Books; 1959. (1990).

Gonsalves T. Chameleon: http://tinagonsalves.com/chamselectframe02.htm; 2009.

Haraway DA. Cyborg manifesto: science, technology, and socialist-feminism in the late twentieth century In: Simians, Cyborgs and Women: the reinvention of nature. New York: Routledge; 1991. p. 149-81.

Healey PG, Light A. When scoring doesn't matter: the aesthetics of performance in arcade games. In: Co Design suppl 1; 2007.

Heidegger M. Being and time. transl. Macquarrie and Robinson. Oxford: Basil Blackwell; 1927, 1962.

Hildebrandt M. Who is profiling who? Invisible visibility. In: Gutwirth S, Poullet Y, De Hert P, de Terwangne C, Nouwt S, editors. Reinventing data protection? Dordrecht: Springer; 2009.

Hulme M, Truch A. The role of interspace in sustaining identity. In: Glotz P, Bertschi S, Locke C, editors. Thumb culture: the meaning of mobile phones for society. Bielefeld: transcript Verlag; 2005. p. 137-148.

Ihde D. Instrumental realism: the interface between philosophy of science and philosophy of technology. Bloomington: Indiana University Press; 1991.

Johnson DG. Computer systems: moral entities but not moral agents. Ethics Inf Technol. 2006;8:195-204.

Kafka F. The trial. transl: Parry I. London: Penguin Modern Classics; 1925. (2007).

Latour B. Reassembling the social: an introduction to actor-network theory. Oxford: Oxford UP; 2005.

Law J, Singleton V. Performing technology's stories: on social constructivism, performance, and performativity. Technol Cult. 2000;41 (4):765-75.

Leonhardt S. Personal healthcare devices. In: Mukherjee S, Aarts RR, Widdershoven F, Ouwerkerk M editors, amIware Hardware Techbology Drivers of Ambient Intelligence. Springer Part 6; 2006.

Light A. The future of computing-visions and reflections. Oxford Internet Institute, OII/e-Horizons Forum Discussion Paper No. 11; 2007.

Light A, Weaver L, Healey PG, Simpson G. Adventures in the not quite yet: using performance techniques to raise design awareness about digital networks In: Proc. DRS; 2008.

Mead GH. Mind, self, and society. Morris CW, editor. Chicago: University of Chicago; 1934.

Merleau-Ponty M. Phenomenology of perception. transl. Smith. London: Routledge; 1945, 1962.

Newell AF, Morgan ME, Gregor P, Carmichael A. Theatre as an intermediary between users and CHI designers. In: Proc CHI'06; 2006.

Orwell G. Nineteen eighty-four. a novel. London: Secker \& Warburg; 1949.

Plant S. Zeros and ones: digital women and the new technoculture. Fourth Estate; 1997.

Rich E, Miah A. Prosthetic surveillance: the medical governance of healthy bodies in cyberspace. Surveillance \& Society. 2009;6(2):163-77.

Rodden T. Ubiquitous computing in the real world, HCI'06 Keynote address; 2006.

Solove DJ. The digital person: technology and privacy in the information age. New York: New York University Press; 2004.

Stiegler B. Technics and time, 1: The fault of Epimetheus. Stanford: Stanford University Press; 1998.

Virilio P. The art of the motor. Minneapolis: University of Minnesota Press; 1996.

Wattson. http://www.diykyoto.com/uk 